\title{
Pacemaker-masked hypertension in a patient with mitral stenosis
}

\author{
JOHN VANN JONES \\ From the Department of Cardiovascular Medicine, Fohn Radcliffe Hospital, Oxford
}

SUMMARY Severe hypertension was seen in a patient with mitral stenosis when in sinus rhythm. Ae large fall in systolic blood pressure and in left ventricular end-diastolic pressure was caused by ventricular pacing. Contrary to the usual situation in mitral stenosis this patient paradoxically is \&O subject who improved haemodynamically with the loss of sinus rhythm and of atrial systole.

Permanent endocardial pacing systems have an established place in the treatment of conduction system disease. Until recently ventricular pacing was the established norm but there are increasing reports that a more "physiological" form of pacing may further enhance cardiac performance. These new systems preserve atrial systole by sequential atrial and ventricular pacing. ${ }^{1}$ Inevitably such systems are being inserted in patients who have concomitant valvular heart disease. There seems little doubt that physiological pacing greatly improves the haemodynamic performance in aortic stenosis. ${ }^{23}$ In mitral stenosis the contribution of atrial systole to cardiac performance is still controversial. About half the published series claims that loss of atrial systole is unimportant. ${ }^{34}$ Others have found the opposite. ${ }^{256}$ This report describes a patient with mitral stenosis in whom ventricular pacing and loss of effective atrial systole lowered peak left ventricular pressure to such an extent that severe concomitant essential hypertension was masked.

\section{Case report}

The patient was a 70-year-old woman who had rheumatic fever in 1918 and has been known to have had rheumatic heart disease since her mid-40's. In 1976 she had a syncopal episode and was diagnosed as having sick sinus syndrome. At least one asystolic episode lasting five seconds was noted during the course of 24-hour electrocardiographic monitoring. As a result she had an ELA lithium pacemaker inserted in November 1976. She has had frequent follow-up visits to both the cardiac clinic and the pacemaker clinic and during these visits her blood pressure has been noted to vary from $270 / 120$ to $160 / 90 \mathrm{mmHg}$.
She had been variably treated with methyldopa an oxprenolol but at the time of subsequent cardiac catheterisation she was on frusemide (40 mg mane) Slow K, digoxin, warfarin and disopyramide.

Her history was of breathlessness on exertion. Thi was very variable as some days she could walk foई three miles on the flat and manage stairs reasonabl $\bar{D}$ well while on other occasions this made her vers breathless.

On physical examination she looked fit and there was no evidence of cardiac failure. Her heart rate was 71 a minute. Blood pressure supine was $160 / 9 \%$ $\mathrm{mmHg}$. The apex beat was left ventricular in type and displaced outwards and downwards. Clinically she had the signs of moderately severe mitral stenosis with only minimal aortic and mitral regurgitation.

Chest $x$-ray film showed moderate cardiomegaly. with some unfolding of the aorta. Her electrocardiog gram, in sinus rhythm, showed left ventricular strai pattern. Echocardiography confirmed the presence of moderately severe mitral stenosis. At cardiac catheter? isation pulmonary artery pressure was around $4 \notin$ mmHg systolic and she had a mean mitral valve gra dient of 7 to $8 \mathrm{mmHg}$. Aortic pressure was $160 / 907$ $\mathrm{mmHg}$ while left ventricular pressure was $160 / 0$ to 100 $\mathrm{mmHg}$. These pressures were obtained during pacing rhythm. While the catheter was in the left ventricles the patient's own sinus rhythm inhibited the pacemaker. There was an immediate rise in the ley ventricular peak pressure and also in end-diastolice pressure (see Fig.). Within 30 seconds this rise waif of the order of $100 \mathrm{mmHg}$, with left ventricular preso sure reaching a value of $260 / 20$ to $30 \mathrm{mmHg}$. There was no aortic gradient. Left ventricular angiograph showed only trivial mitral regurgitation while an ao togram showed mild aortic regurgitation only. Selecs 

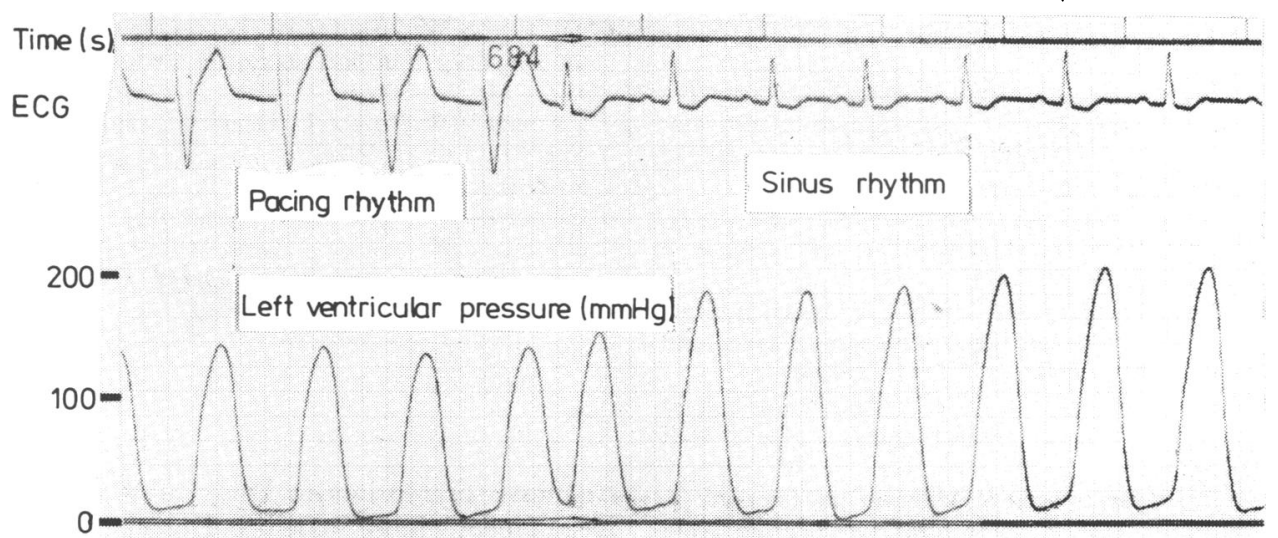

Fig. Simultaneous left ventricular pressure trace and electrocardiogram. When the patient's own sinus rhythm inhibits the pacemaker there is an immediate increase in both left ventricular peak and end-diastolic pressures.

tive coronary arteriograms showed these vessels to be natural and free from disease.

\section{Discussion}

Harvey, in 1628 , noted that when the ventricle of the frog was cut open fluid spurted from it in time with contraction of the atria. The active part played by atrial systole in ventricular filling has been controversial ever since. When such factors as heart rate, $P R$ interval, and ventricular diastolic volume are taken into account, however, there seems little doubt that atrial systole contributes around 10 to $20 \%$ of left ventricular output in normal hearts. ${ }^{7}$

In mitral stenosis the diastolic gradient increases with atrial systole and so does the diastolic flow across the valve. Thus, factors such as heart rate (and therefore duration of diastole) and severity of stenosis will determine the contribution of atrial systole to left ventricular filling. In severe mitral stenosis atrial systole will be needed to force blood through the valve and to increase ventricular end-diastolic volume and hence cardiac output.

The loss of sinus rhythm in mitral stenosis generally leads to haemodynamic deterioration. The fibrillating atria no longer contract effectively, thus reducing the diastolic gradient over the valve and hence diastolic flow while the rapid heart rate and shortened diastole further reduce diastolic ventricular filling. In our patient paradoxically the loss of sinus rhythm seemed to have beneficial haemodynamic effects. While pacing the blood pressure was normal as was her left ventricular end-diastolic pressure. With pacemaker inhibition and the return of sinus rhythm, end-diastolic pressure trebled and systolic blood pressure increased by up to $100 \mathrm{mmHg}$ and she was clearly hypertensive. The haemodynamic changes seen with pacing were likely to be sustained as the patient was seen on many occasions at the clinic when she was in pacing rhythm and her blood pressure was normal.

It is interesting to speculate upon the mechanism of the raised end-diastolic pressure which was presumably the reason why some days the exercise tolerance was substantially better than others. It seems that a combination of increased preload (right atrial systole increasing right ventricular output and left atrial pressure) and increased afterload both contribute (left atrial systole increasing diastolic flow into the left ventricle, and cardiac output increasing into what was presumably a cardiovascular system with a relatively increased and fixed resistance). Support for this comes from Chamberlain et al., ${ }^{1}$ who showed that sequential atrioventricular pacing in patients with heart disease (admittedly not involving the valves) resulted in a fall in central venous pressure and a rise in systemic blood pressure.

In our patient it is also possible that paced beats were less efficient and that the paced ventricle could not generate the power to raise the blood pressure. It has been shown that the left ventricle produces less stroke work for a given end-diastolic pressure during ventricular pacing ${ }^{8}$ and that the rate of ventricular contraction is reduced. Diastole is also thus shortened, with presumably a consequent fall in flow across the valve especially if the valve is stenosed.

In any event though both the pacing and sinus heart rates were virtually identical (see Fig.) the circulatory status of the patient changed conspicuously for the better with the loss of atrial systole, thus supporting the view that atrial systole does have haemodynamic significance in mitral stenosis. In this particular patient it was of such a magnitude that severe systemic hypertension was masked when atrial systole was lost. 


\section{References}

1 Chamberlain DA, Leinbach RC, Vassaux CE, Kastor JA, I) Sanctis RW, Sanders CA. Sequential atrioventricular pacing in heart block complicating acute myocardial infarction. $N$ Engl f Med 1980; 282: 577-82.

2 Heidenreich FP, Shaver JA, Thompson ME, Leonard JJ. Left atrial booster function in valvular heart disease. $\mathcal{F}$ Clin Invest 1970; 49: 1605-18.

3 Stott DK, Marpole DGF, Bristow JD, Kloster FE, Griswold HE. The role of left atrial transport in aortic and mitral stenosis. Circulation 1970; 41: 1031-41.

4 Carleton RA, Graehinger JS. The haemodynamic role of the atria with and without mitral stenosis. Am $\mathcal{F}$ Med 1967; 42: 532-8.

5 Heidenreich FP, Thompson ME, Shaver JA, Leonard JJ. Left atrial transport in mitral stenosis. Circulation 1969; 40: 545-54.
6 Thompson ME, Shaver JA, Leon DF. Effect of tachycardia on atrial transport in mitral stenosis. Am Heart 1977; 94: 297-306.

7 Parmley WW, Talbot L. Heart as a pump. In: Berne $R$ Sperelakis N, eds. Handbook of physiology: the cardiovascis lar system. Baltimore: Waverly Press, 1979: 429-60.

8 Gilmore JP, Sarnoff SJ, Mitchell JH, Linden RJ. Syr chronicity of ventricular contraction: observations cons paring haemodynamic effects of atrial and ventricular pa६ ing. Br Heart f 1963; 25: 299-307.

Requests for reprints to Dr John V Jones, Cardiac Department, John Radcliffe Hospital, Headington Oxford OX3 9DU. 